\title{
AUDIT SISTEM INFORMASI
}

SMK FARMASI CENDIKIA FARMA HUSADA

(DEVISI TATA USAHA)

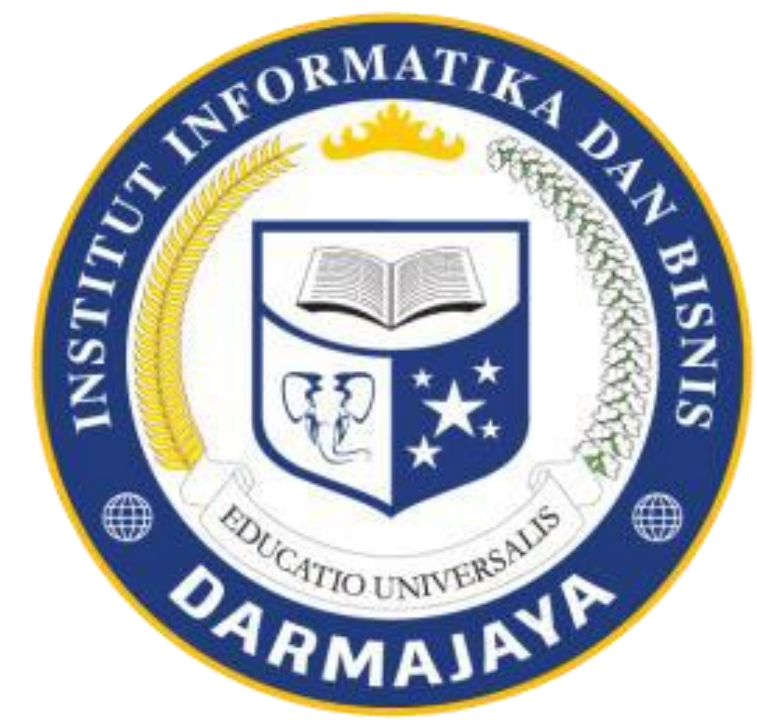

EKA NATALIA PUTRI

1611050137

P03

INSTITUT INFORMATIKA DAN BISNIS DARMAJAYA

Bandar Lampung

2019 


\section{BAB I}

\section{SEJARAH SMK FARMASI CENDIKIA FARMA HUSADA}

Sekolah menengah kejuruan (SMK) farmasi cendikia farma husada dirintis sejak mei 2010 oleh praktisi apotikermuda yang berfossional dan kompeten dibidang kefarmasian yaitu Bpk.Hi ardyansyah khauripan, M,Si., Apt dibawah naungan yayasan cendikia farma husada.

SMK farmasi candika husada ini merupakan smk farmasi yang pertama berada diBandar Lampung yang kemuduan menjadi pelopor perkembangan smk farmasi diprovinsi Lampung. Sebagai sekolah farmasi plopor, SMK farmasi cendika terus melakukan pengebangan sistem kependiddikan farmasi sehinga tampil menjadi SMK farmasi favorit dan unggul.

Secara geografis gedung SMK farmasi cendikia farma husada terletak dilingkingan pemungkiman penduduk dikota Bandar Lampung tempatnya dijalan pulau enggano No.99, Kelurahan Sukabumi, Kecamatan Sukabumi, kota Bandar Lampung. Sekolah ini berdiri diatas tanah seluas $\pm 1.878 \mathrm{~m}^{2}$.

Secara topografi wilayah SMK farmasi cendikia farma husada merupakan daerah dataran yang subur dengan sumber air yang baik. Akses menuju sekolah dapat ditempuh dengan roda empat maupun roda dua.

Tata ruang gedung SMK farmasi candikia farma husada dibangun dengan konsep modren dan humanis sehingga interaksi guru dan siswa dalam proses pendidikan dapat terbangun dan terpelihara dengan baik. SMK farmasi candikia farma husada menyajikan fasilitas belajar yang nyaman dan memadai yaitu:

1. Gedung sekolah yang fresh dengan status milik sendiri (yayasan cendikia farma husada).

2. Laborarorium praktikum farmasetika yang lengkap dan ber-AC.

3. Ruang kelas multimedia (audio-visual/lcd proyektor) dan ber-AC.

4. Wifi/host spot area.

5. Perpustakaan

6. Kantin yang bersih dan nyaman

7. Mushola

8. Ruang perawatan kesehatan

9. Ruang sekretariat bersama unit kegiatan siswa

10. Lapangan bulu tangkis dan sepak takraw

11. Area parkir dan taman

12. Apotek pendidikan

13. Kebun tanaman obat

14. Fasilitas sanitasi yang baik.

Letak sekolah yang tidak terlalu dekat dengan jalan raya menjadi nilai positif secara ekologis, sekolah tiadak bisik dan mengurangi kontaminasi dari polusi timbal yang berbahaya bagi pernafasan. Letak sekolah yang lebih tinggi dari jalan umum serta sistem irigasi yang lancar dan baik dapat menghindari sekolah dari banjir pada musim hujan. 
VISI DAN MISI SMK FARMASI CENDIKIA FARMA HUSADA

* VISI

"mewujudkan sekolah yang unggul dalam mencetak asisten tenaga kefarmasian yang kompeten,disiplin,religius dan berdaya saing".

MISI

1. Membangkitan kekuatan moral dan kesadaran tentang keberadaan Allah SWT Yang Masha Esa dan sadar bahwa setiap kehidupan akan dipertanggung jawabkan .

2. Menyelenggarakan proses pendidikan yang professional dan berkualitas agar peserta didik menjadi asisten tenaga kefarmasian yang berkemampuan akademik dan berdaya asing.

3. Melakukan pendidikan dan pengembangan karakter peserta didik agar memiliki kecerdasan emosional dan spiritual yang baik dalam menerapkan ilmu kefarmasian dimasyarakat.

4. Menggunakan teknologi informasi dalam penyelenggaraan pendidikan serta mengupayakan kemampuan penggunananya kepada peserta didik untuk meningkatkan daya asing diera digital.

\section{FRESTASI SMK FARMASI CENDIKIA FARMA HUSADA}

1. Juara $1 \mathrm{lks}$ tingkat kota bandar lampung

2. Juara 1 olimpiade sains terapan (ost) bidang biologi se provinsi lampung

3. Juara 1 lomba kompetisi siswa (lks) se provinsi lampung

4. Smk faramasi cendikia farma husada mendapat penghargaan dari mentri pendididkan nasional RI sebagai sekolah berintegritas tinggi tahun 2015

\section{SMK FARMASI CENDIKIA FARMA HUSADA BERGERAK DIBIDANG}

"Yayasan Cendikia Farma Husada”

DENAH LOKASI SMK FARMASI CENDIKIA FARMA HUSADA

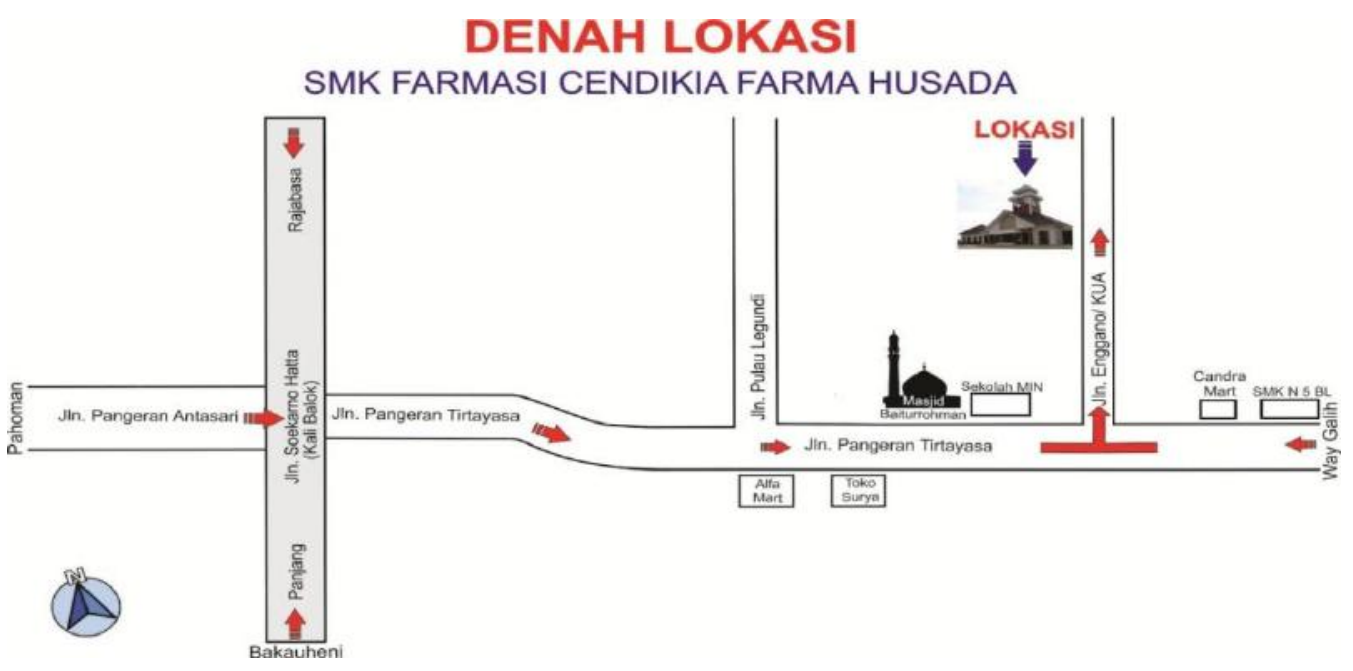




\section{BAB II}

\section{STRUKTUR SMK FARMASI CENDIKIA FARMA HUSADA}

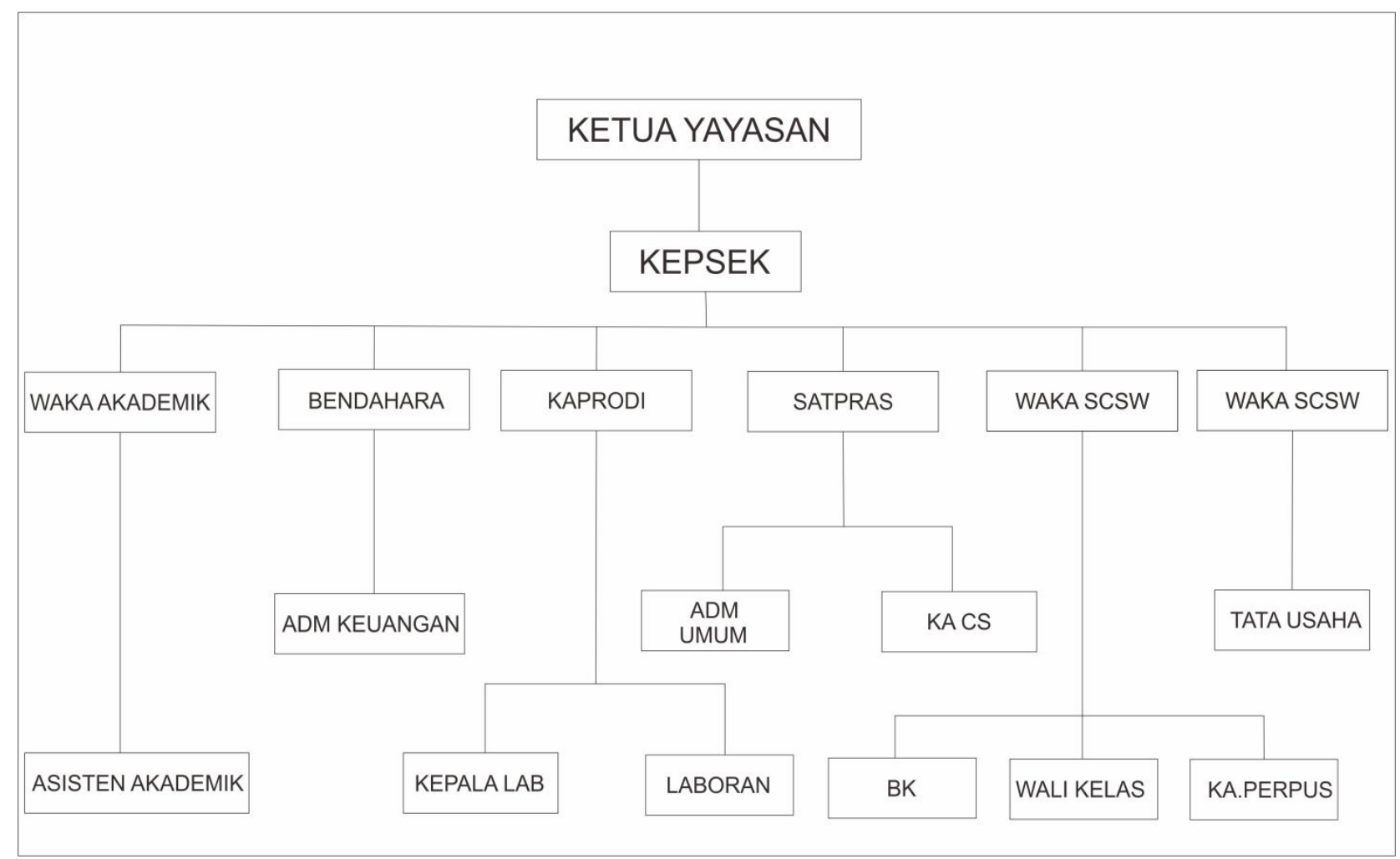

\section{STRUKTUR DIVISI TATA USAHA}

STRUKTUR KEPALA TATA USAHA

KEPALA A TU

TATA USAHA 


\section{BAB III}

\begin{tabular}{|c|c|c|c|c|c|c|c|c|c|c|c|}
\hline \multirow[b]{2}{*}{ No } & \multirow[b]{2}{*}{ Persyaratan } & \multicolumn{5}{|c|}{ Performance } & \multicolumn{5}{|c|}{ Expectasi } \\
\hline & & $\begin{array}{l}\mathrm{S} \\
\mathrm{B}\end{array}$ & $\mathrm{B}$ & $\mathrm{C}$ & $\begin{array}{l}\mathrm{T} \\
\mathrm{B}\end{array}$ & $\begin{array}{l}\mathrm{ST} \\
\mathrm{R}\end{array}$ & $\begin{array}{l}\mathrm{S} \\
\mathrm{B}\end{array}$ & $\mathrm{B}$ & $\mathrm{C}$ & $\begin{array}{l}\mathrm{T} \\
\mathrm{B}\end{array}$ & $\begin{array}{l}\text { ST } \\
\text { R }\end{array}$ \\
\hline \multicolumn{12}{|c|}{ AI3 Memperoleh dan Memelihara Infrastruktur Teknologi } \\
\hline \multicolumn{12}{|c|}{ AI3.1 Rencana pemerolehan infrastruktur teknologis } \\
\hline 1. & $\begin{array}{l}\text { Apakah data kehadiran para siswa } \\
\text { disekolah sudah terkomputerisasi? }\end{array}$ & & & & & & & & & & \\
\hline 2. & $\begin{array}{l}\text { Bagaimana penerapan dan } \\
\text { pemeliharaan sistem kehadiran para } \\
\text { siswa disekolah? }\end{array}$ & & & & & & & & & & \\
\hline \multicolumn{12}{|c|}{ AI3.2 Perlindungan dan ketersediaan sumber daya infrastruktur } \\
\hline 1. & $\begin{array}{l}\text { Bagaimana keamanan yang diterapkan } \\
\text { untuk melindungi data para siswa? }\end{array}$ & & & & & & & & & & \\
\hline 2. & $\begin{array}{l}\text { Bagaimana pertanggungjawaban } \\
\text { terhadap penyalahgunaan stempel } \\
\text { sekolah? }\end{array}$ & & & & & & & & & & \\
\hline \multicolumn{12}{|c|}{ AI3.3 Pemeliharaan infrastruktur } \\
\hline 1. & $\begin{array}{l}\text { Bagaimana menjaga data para siswa } \\
\text { yang sudah terdata disekolah? }\end{array}$ & & & & & & & & & & \\
\hline 2. & $\begin{array}{l}\text { Bagaimana strategi yang dilakukan } \\
\text { untuk membuat sistem kehadiran para } \\
\text { siswa menjadi akurat? }\end{array}$ & & & & & & & & & & \\
\hline
\end{tabular}

AI3.4 Lingkungan uji kelayakan

1. Bagaimana mengatasi kegagalan dalam mendidik para siswa?

Bagaimana strategi yang digunakan

2. untuk membuat para siswa dapat menaati peraturan di sekolah?

DS8 Mengelola Layanan dan Insiden

DS8.1 Bagian jasa

Bagaimana prosedur yang ada untuk

1. mendapatkan suatu informasi baik akademik maupun non akademik?

Bagaimana meningkatkan pelayanan

2. di bagian akademik untuk

memudahkan para siswa memperoleh informasi?

DS8.2 Pendaftaran query pelanggan

Apakah sistem yang dibangun sudah

1. dapat membantu para siswa untuk mendapatkan suatu informasi yang diinginkan?

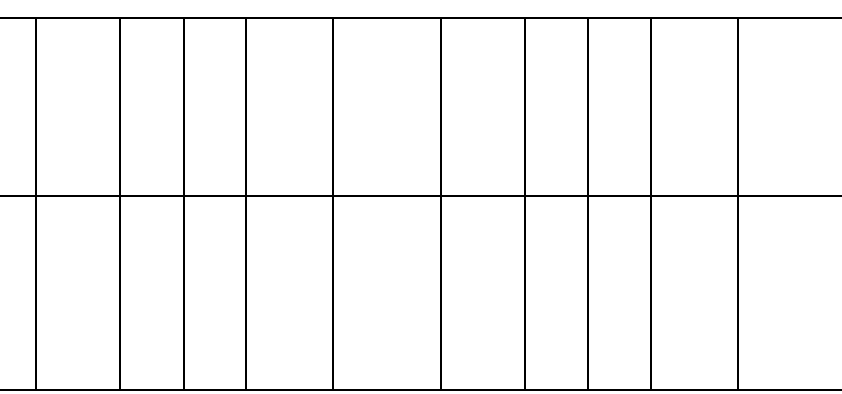




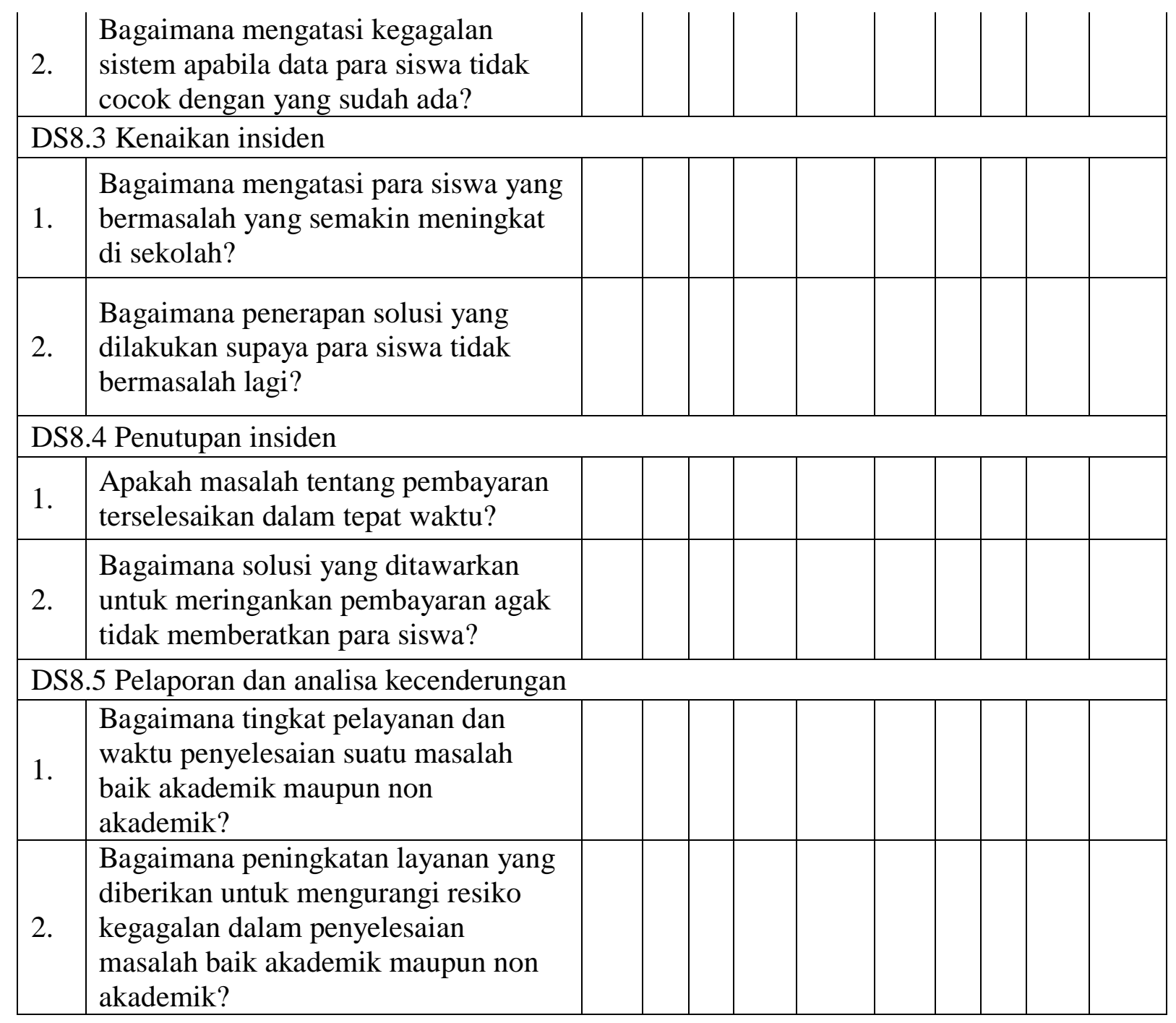




\section{BAB IV}

REKAP HASIL KUESIONER

USER

\begin{tabular}{|c|c|c|c|c|c|c|c|c|c|c|c|c|c|c|}
\hline & \multicolumn{7}{|c|}{ PERFORMANCE } & \multicolumn{6}{|c|}{ EXPECTED } \\
\hline & & No & SB & B & $C$ & TB & STB & JLH & SB & B & C & TB & STB & JLH \\
\hline 1 & $\mathrm{Al} 3.1$ & 1,1 & & 5 & 3 & & & 8 & 5 & 3 & & & & 8 \\
\hline 2 & & 1,2 & 1 & 6 & 1 & & & 8 & 7 & 1 & & & & 8 \\
\hline 3 & $\mathrm{Al} 3.2$ & 2,1 & 2 & 3 & 2 & 1 & & 8 & 5 & 3 & & & & 8 \\
\hline 4 & & 2,2 & 3 & 1 & 4 & & & 8 & 6 & 2 & & & & 8 \\
\hline 5 & $\mathrm{Al} 3.3$ & 3,1 & 2 & 4 & 2 & & & 8 & 7 & 1 & & & & 8 \\
\hline 6 & & 3,2 & & 4 & 4 & & & 8 & 5 & 3 & & & & 8 \\
\hline 7 & $\mathrm{Al} 3.4$ & 4,1 & 1 & 2 & 5 & & & 8 & 4 & 4 & & & & 8 \\
\hline 8 & & 4,2 & 2 & 3 & 3 & & & 8 & 8 & & & & & 8 \\
\hline 9 & DS8.1 & 1,1 & 1 & 5 & 1 & 1 & & 8 & 6 & 2 & & & & 8 \\
\hline 10 & & 1,2 & 1 & 3 & 4 & & & 8 & 4 & 4 & & & & 8 \\
\hline 11 & DS8.2 & 2,1 & 1 & 5 & 2 & & & 8 & 6 & 2 & & & & 8 \\
\hline 12 & & 2,2 & 1 & 3 & 4 & & & 8 & 6 & 2 & & & & 8 \\
\hline 13 & DS8.3 & 3,1 & 3 & 2 & 3 & & & 8 & 7 & 1 & & & & 8 \\
\hline 14 & & 3,2 & 3 & 2 & 1 & 2 & & 8 & 6 & 2 & & & & 8 \\
\hline 15 & DS8.4 & 4,1 & & 5 & 3 & & & 8 & 5 & 3 & & & & 8 \\
\hline 16 & & 4,2 & 1 & 3 & 4 & & & 8 & 6 & 2 & & & & 8 \\
\hline 17 & DS8.5 & 5,1 & 1 & 6 & 1 & & & 8 & 8 & & & & & 8 \\
\hline 18 & & 5,2 & & 4 & 4 & & & 8 & 7 & 1 & & & & 8 \\
\hline
\end{tabular}

\begin{tabular}{|c|c|c|c|c|}
\hline \multicolumn{2}{|c|}{ PERFORMANCE } & \multicolumn{2}{|c|}{ EXPECTED } & \multirow{3}{*}{ gap } \\
\hline \multicolumn{4}{|c|}{ MATURITY } & \\
\hline ACTIVITY & PROSES & ACTIVITY & PROSES & \\
\hline 1,93 & \multirow{2}{*}{2,03} & 2,47 & \multirow{2}{*}{2,53} & \multirow[b]{2}{*}{0,50} \\
\hline 2,13 & & 2,60 & & \\
\hline 2,00 & \multirow{2}{*}{2,03} & 2,47 & \multirow{2}{*}{2,50} & \multirow[b]{2}{*}{0,47} \\
\hline 2,07 & & 2,53 & & \\
\hline 2,13 & \multirow{2}{*}{2,00} & 2,60 & \multirow{2}{*}{2,53} & \multirow[b]{2}{*}{0,53} \\
\hline 1,87 & & 2,47 & & \\
\hline 1,87 & \multirow{2}{*}{1,97} & 2,40 & \multirow{2}{*}{2,53} & \multirow[b]{2}{*}{0,57} \\
\hline 2,07 & & 2,67 & & \\
\hline 2,00 & \multirow{2}{*}{1,97} & 2,53 & \multirow{2}{*}{2,47} & \multirow[b]{2}{*}{0,50} \\
\hline 1,93 & & 2,40 & & \\
\hline 2,07 & \multirow{2}{*}{2,00} & 2,53 & \multirow{2}{*}{2,53} & \multirow[b]{2}{*}{0,53} \\
\hline 1,93 & & 2,53 & & \\
\hline 2,13 & \multirow{2}{*}{2,07} & 2,60 & \multirow{2}{*}{2,57} & \multirow[b]{2}{*}{0,50} \\
\hline 2,00 & & 2,53 & & \\
\hline 1,93 & \multirow{2}{*}{1,93} & 2,47 & \multirow{2}{*}{2,50} & \multirow[b]{2}{*}{0,57} \\
\hline 1,93 & & 2,53 & & \\
\hline 2,13 & \multirow{2}{*}{2,00} & 2,67 & \multirow{2}{*}{2,63} & \multirow[b]{2}{*}{0,63} \\
\hline 1,87 & & 2,60 & & \\
\hline
\end{tabular}




\begin{tabular}{|c|c|c|c|c|c|c|c|c|c|c|c|c|c|c|}
\hline & \multicolumn{7}{|c|}{ PERFORMANCE } & \multicolumn{6}{|c|}{ EXPECTED } \\
\hline & & No & SB & B & C & TB & STB & JLH & SB & B & C & TB & STB & JLH \\
\hline 1 & \multirow[t]{2}{*}{ Al3.1 } & 1,1 & 2 & 2 & & & & 4 & \multicolumn{4}{|c|}{4} & \multicolumn{2}{|r|}{4} \\
\hline 2 & & 1,2 & 1 & 2 & \multicolumn{3}{|l|}{1} & 4 & \multicolumn{5}{|c|}{4} & 4 \\
\hline 3 & \multirow[t]{2}{*}{ Al3.2 } & 2,1 & 1 & 2 & \multicolumn{3}{|l|}{1} & 4 & \multicolumn{5}{|c|}{4} & 4 \\
\hline 4 & & 2,2 & & 2 & \multicolumn{3}{|l|}{2} & 4 & 3 & \multicolumn{4}{|l|}{1} & 4 \\
\hline 5 & \multirow[t]{2}{*}{ Al3.3 } & 3,1 & 1 & 2 & \multicolumn{3}{|l|}{1} & 4 & \multicolumn{5}{|c|}{4} & 4 \\
\hline 6 & & 3,2 & 2 & 1 & \multicolumn{3}{|l|}{1} & 4 & 3 & \multicolumn{4}{|l|}{1} & 4 \\
\hline 7 & \multirow[t]{2}{*}{$\mathrm{Al} 3.4$} & 4,1 & & 1 & \multicolumn{3}{|l|}{3} & 4 & 1 & \multirow{2}{*}{\multicolumn{4}{|c|}{3}} & 4 \\
\hline 8 & & 4,2 & & 3 & \multicolumn{3}{|l|}{1} & 4 & 4 & & & & & 4 \\
\hline 9 & \multirow[t]{2}{*}{ DS8.1 } & 1,1 & 3 & 1 & \multicolumn{3}{|c|}{ L } & 4 & \multicolumn{5}{|c|}{4} & 4 \\
\hline 10 & & 1,2 & 3 & 1 & \multicolumn{3}{|c|}{1} & 4 & \multicolumn{5}{|c|}{4} & 4 \\
\hline 11 & \multirow[t]{2}{*}{ DS8.2 } & 2,1 & 1 & 3 & \multirow{2}{*}{\multicolumn{3}{|c|}{1}} & 4 & 4 & & & & & 4 \\
\hline 12 & & 2,2 & & 3 & & & & 4 & 3 & \multicolumn{4}{|l|}{1} & 4 \\
\hline 13 & \multirow[t]{2}{*}{ DS8.3 } & 3,1 & 1 & 1 & 2 & & & 4 & 2 & 2 & & & & 4 \\
\hline 14 & & 3,2 & 1 & 1 & 2 & & & 4 & 4 & & & & & 4 \\
\hline 15 & DS8.4 & 4,1 & 1 & 3 & & & & 4 & 4 & & & & & 4 \\
\hline 16 & & 4,2 & 3 & 1 & & & & 4 & 4 & & & & & 4 \\
\hline 17 & DS8.5 & 5,1 & 4 & & & & & 4 & 4 & & & & & 4 \\
\hline 18 & & 5,2 & 2 & 2 & & & & 4 & 4 & & & & & 4 \\
\hline
\end{tabular}

\begin{tabular}{|c|c|c|c|c|}
\hline \multicolumn{2}{|c|}{ PERFORMANCE } & \multicolumn{2}{|c|}{ EXPECTED } & \multirow{3}{*}{ gap } \\
\hline \multicolumn{4}{|c|}{ MATURITY } & \\
\hline ACTIVITY & PROSES & ACTIVITY & PROSES & \\
\hline 3,60 & \multirow{2}{*}{3,40} & 4,00 & \multirow{2}{*}{4,00} & \multirow[b]{2}{*}{0,60} \\
\hline 3,20 & & 4,00 & & \\
\hline 3,20 & \multirow{2}{*}{3,00} & 4,00 & \multirow{2}{*}{3,90} & \multirow[b]{2}{*}{0,90} \\
\hline 2,80 & & 3,80 & & \\
\hline 3,20 & \multirow{2}{*}{3,30} & 4,00 & \multirow{2}{*}{3,90} & \multirow[b]{2}{*}{0,60} \\
\hline 3,40 & & 3,80 & & \\
\hline 2,60 & \multirow{2}{*}{2,80} & 3,40 & \multirow{2}{*}{3,70} & \multirow[b]{2}{*}{0,90} \\
\hline 3,00 & & 4,00 & & \\
\hline 3,80 & \multirow{2}{*}{3,80} & 4,00 & \multirow{2}{*}{4,00} & \multirow[b]{2}{*}{0,20} \\
\hline 3,80 & & 4,00 & & \\
\hline 3,40 & \multirow{2}{*}{3,20} & 4,00 & \multirow{2}{*}{3,90} & \multirow[b]{2}{*}{0,70} \\
\hline 3,00 & & 3,80 & & \\
\hline 3,00 & \multirow{2}{*}{3,00} & 3,60 & \multirow{2}{*}{3,80} & \multirow[b]{2}{*}{0,80} \\
\hline 3,00 & & 4,00 & & \\
\hline 3,40 & \multirow{2}{*}{3,60} & 4,00 & \multirow{2}{*}{4,00} & \multirow[b]{2}{*}{0,40} \\
\hline 3,80 & & 4,00 & & \\
\hline 4,00 & \multirow{2}{*}{3,80} & 4,00 & \multirow{2}{*}{4,00} & \multirow[b]{2}{*}{0,20} \\
\hline 3,60 & & 4,00 & & \\
\hline
\end{tabular}




\begin{tabular}{ccccc} 
& \multicolumn{2}{c}{ CURRENT } & \multicolumn{2}{c}{ Expectacy } \\
& USER & MGT & User & MGT \\
Al3.1 & 2,03 & 4,00 & 2,53 & 4,00 \\
Al3.2 & 2,03 & 4,00 & 2,50 & 3,90 \\
Al3.3 & 2,00 & 4,00 & 2,53 & 3,90 \\
Al3.4 & 1,97 & 3,40 & 2,53 & 3,70 \\
DS8.1 & 1,97 & 4,00 & 2,47 & 4,00 \\
DS8.2 & 2,00 & 4,00 & 2,53 & 3,90 \\
DS8.3 & 2,07 & 3,60 & 2,57 & 3,80 \\
DS8.4 & 1,93 & 4,00 & 2,50 & 4,00 \\
DS8.5 & 2,00 & 4,00 & 2,63 & 4,00
\end{tabular}

\section{Perhitungan User \& Manajement}

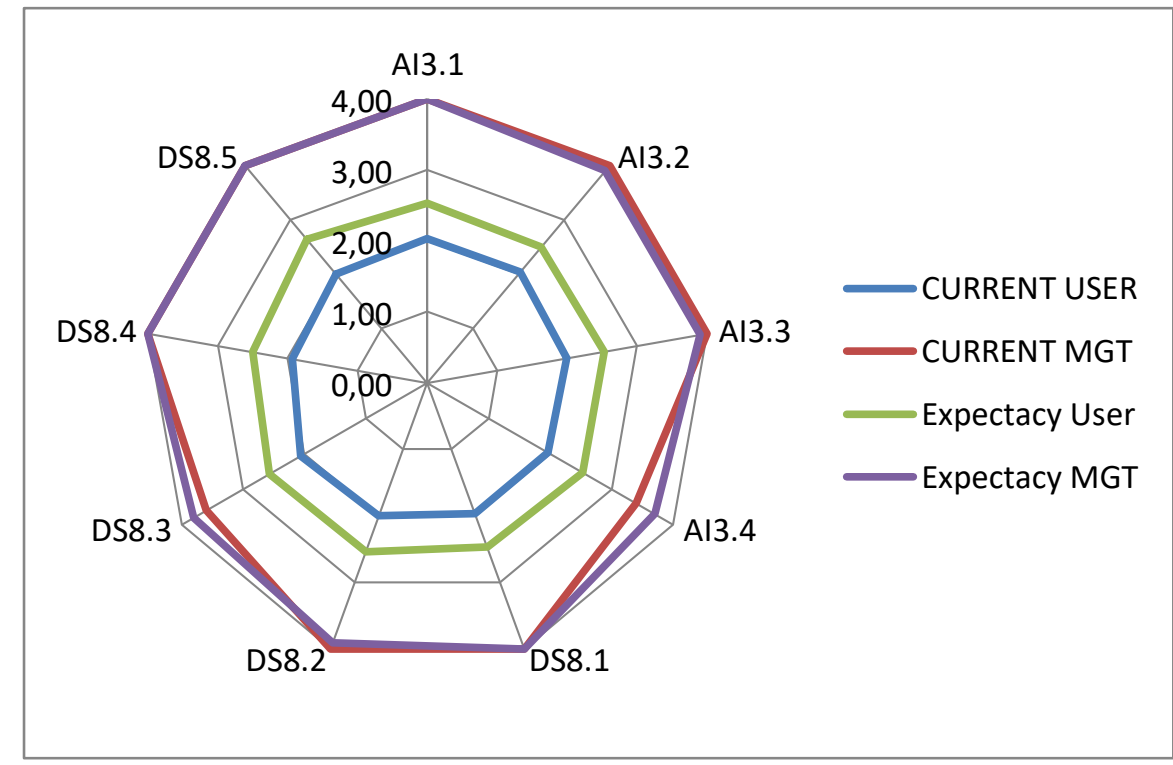

\section{Perhitungan USER}

$\begin{array}{lrr} & \begin{array}{c}\text { CURRENT } \\ \text { USER }\end{array} & \begin{array}{c}\text { Expectacy } \\ \text { User }\end{array} \\ \text { Al3.1 } & 2,03 & 2,47 \\ \text { Al3.2 } & 2,03 & 2,47 \\ \text { Al3.3 } & 2,00 & 2,60 \\ \text { Al3.4 } & 1,97 & 2,40 \\ \text { DS8.1 } & 1,97 & 2,53 \\ \text { DS8.2 } & 2,00 & 2,53 \\ \text { DS8.3 } & 2,07 & 2,60 \\ \text { DS8.4 } & 1,93 & 2,47 \\ \text { DS8.5 } & 2,00 & 2,67\end{array}$

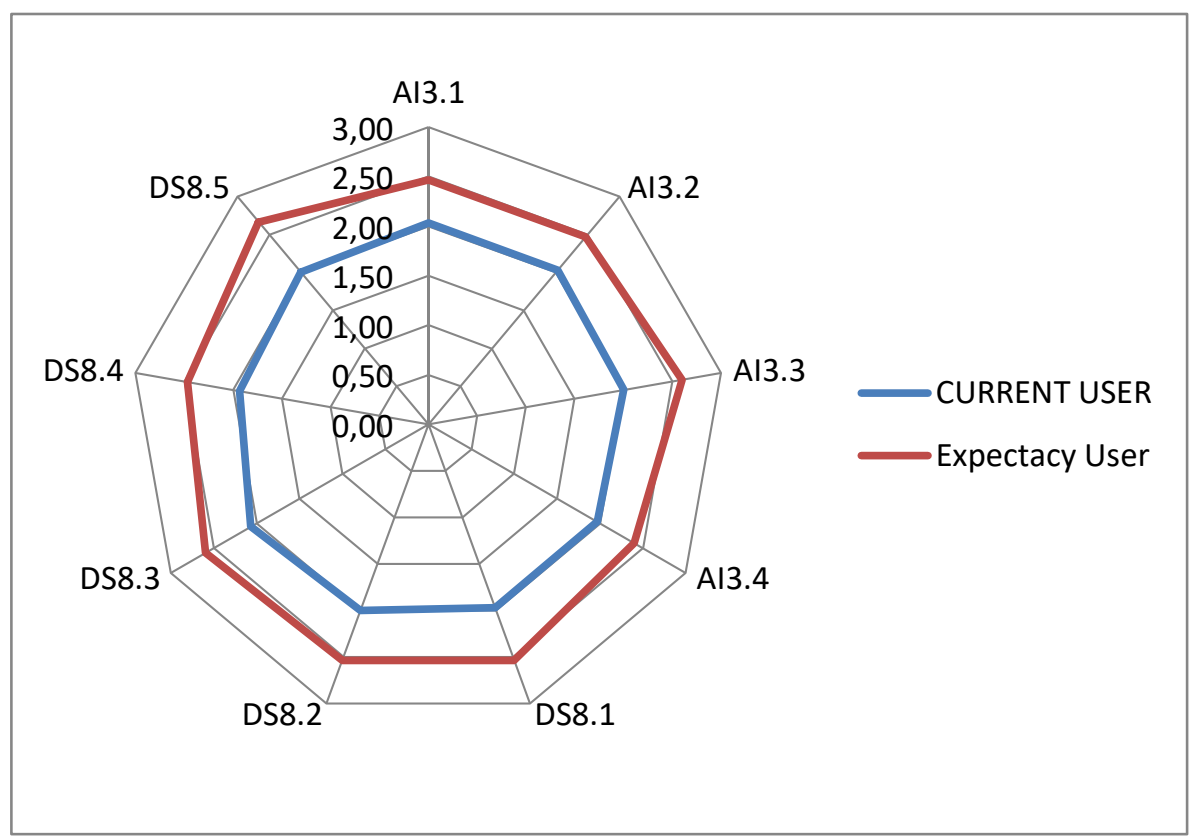




\section{Perhitungan Manajement}

$\begin{array}{lrcc} & \text { CURRENT } & \text { Expectacy } \\ \text { MIS.1 } & 4,00 & 4,00 \\ \text { Al3.2 } & 4,00 & 3,90 \\ \text { Al3.3 } & 4,00 & 3,90 \\ \text { Al3.4 } & 3,40 & 3,70 \\ \text { DS8.1 } & 4,00 & 4,00 \\ \text { DS8.2 } & 4,00 & 3,90 \\ \text { DS8.3 } & 3,60 & 3,80 \\ \text { DS8.4 } & 4,00 & 4,00 \\ \text { DS8.5 } & 4,00 & 4,00\end{array}$




\section{BAB V}

\section{Saran}

- Lebih baik lagi dalam pelayanan akademik maupun non akademik

- Lebih menjaga data para siswa agar lebih aman

○ Lebih meningkatkan sistem yang ada disekolah

\section{Kesimpulan}

Dari hasil audit yang dilakukan di SMK FARMASI CENDIKIA FARMA HUSADA sudah cukup baik dalam segi pelayanan akademik dan non akademik yang berada dalam sekolah, sudah cukup menfasilitasi para siswa dengan fasilitas yang ada, dan sistem yang digunakan sudah terkomputerisasi. 


\section{LAMPIRAN}

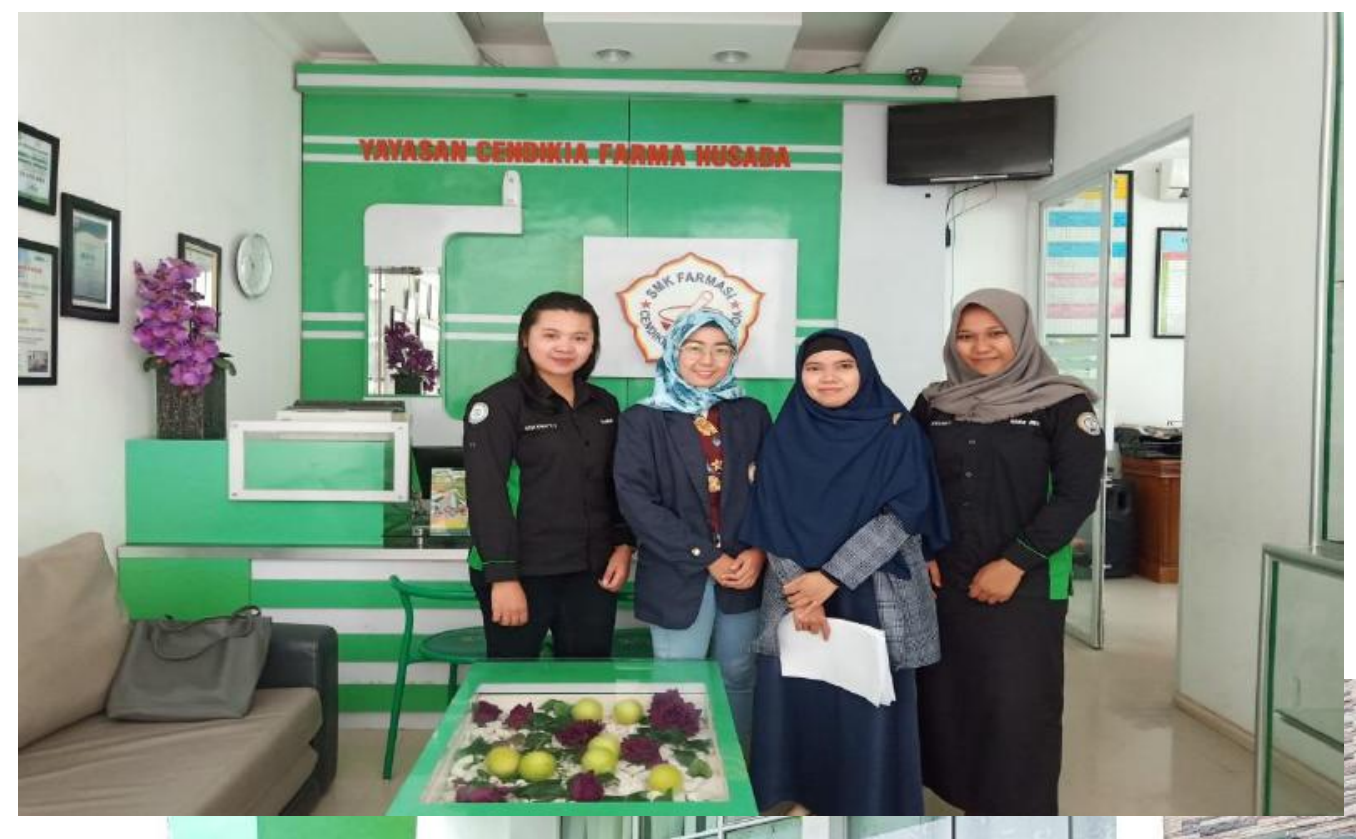

Saren Ser -5 kistit

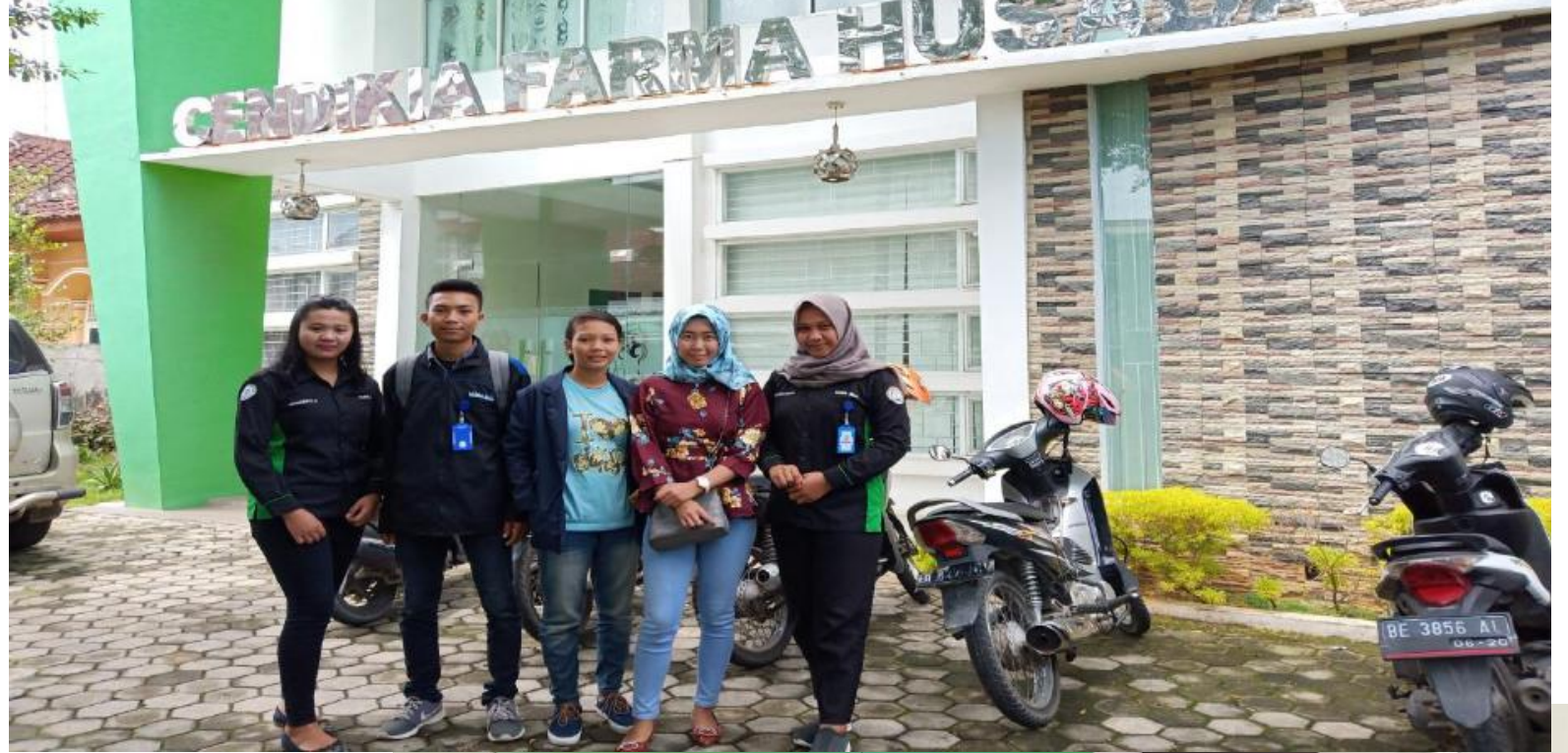

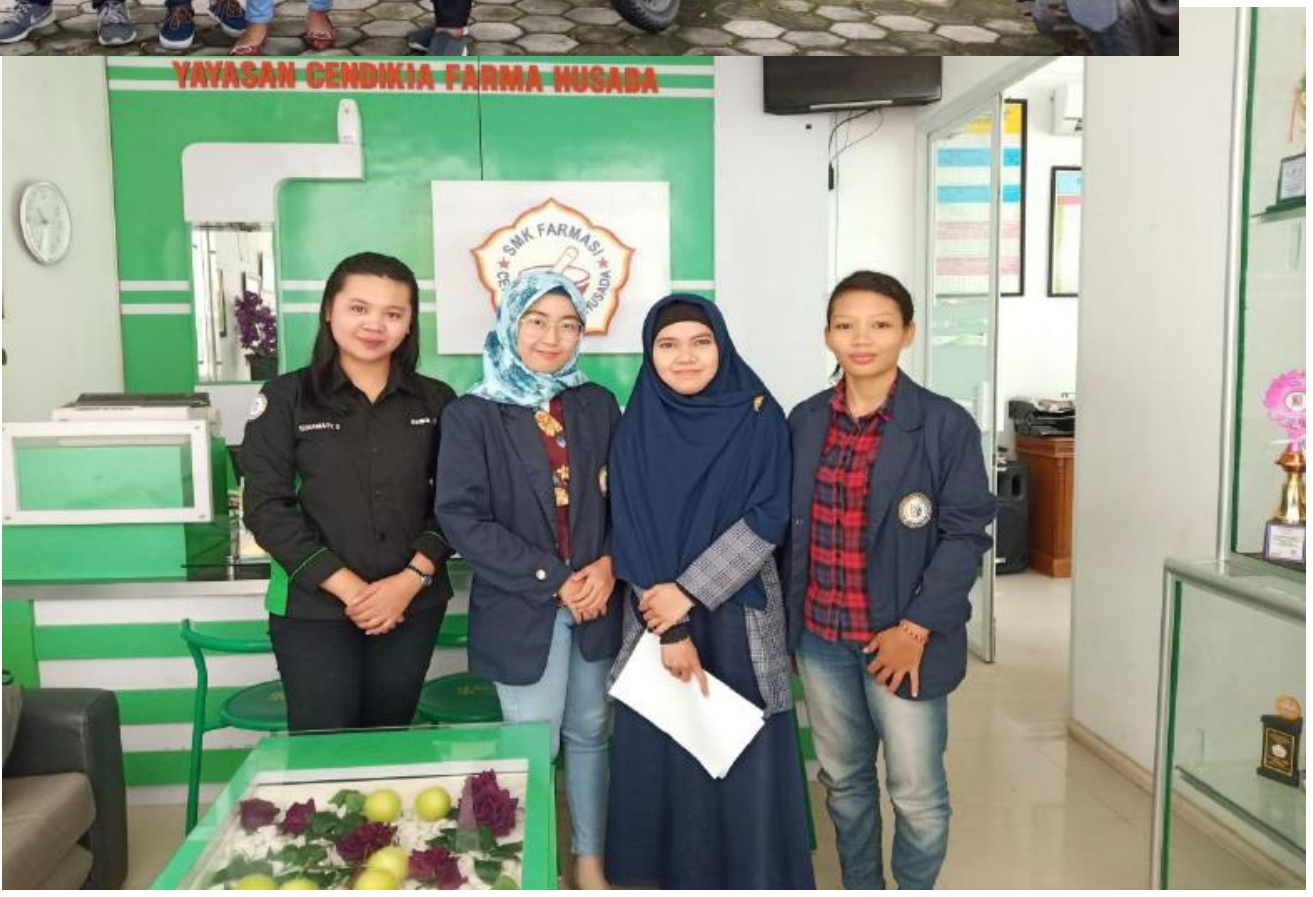

